\title{
ESTUDO PARASITOLÓGICO E ANÁTOMO-PATOLÓGICO DA FASE AGUDA DA DOENÇA DE CHAGAS EM CÃES INOCULADOS COM DUAS DIFERENTES CEPAS DO TRYPANOSOMA CRUZI
}

\author{
Maria Alice Pedreira de Castro e Zigman Brener
}

\begin{abstract}
Cães jovens foram infectados com as cepas $Y$ e $C L$ do $\mathrm{T}$. cruzi usando-se como inóculos $10^{7}$ formas sangüineas inoculadas por via intraperitoneal e $2 \times 10^{3}$ tripomastigotas metaciclicos obtidos do inseto vetore inoculados por via conjuntival. As cepas $Y e$ CL induziram nos cães curvas de parasitemia totalmente distintas, confirmando dados parasitológicos obtidos em camundongos e coelhos. Com a cepa CL a parasitemia, com ambos os inóculos, foi gradualmente ascencional ao passo que com Y a parasitemia foi extremamente baixa, irregular e, com freqüencia, subpatente. Com ambas as cepas o parasitismo e as lesöes predominaram no miocárdio. Entretanto, com a cepa $Y$ a miocardite foi sempre intensa desde as fases mais precoces da infecção, ao passo que com a cepa $C L$ o processo inflamatório tornou-se acentuado somente a partir do $200^{\circ}$ dia. Freqüentemente a intensidade da miocardite observada em alguns animais não guardava relação com a parasitemia; em alguns cães com parasitemia subpatente, nos quais a infecção só foi diagnosticada pelo xenodiagnóstico, a intensidade da miocardite foi comparável àquela observada nos animais com parasitemia patente. Idêntica correlaçâo também não foi assinalada em relação ao parasitismo tissular. Esses achados sugerem a participação de mecanismo imunológicos na gênese das lesões, ainda na fase aguda da infecção.
\end{abstract}

Palavras Chaves: Trypanosoma cruzi. Cepas Y e CL. Miocardite experimental em cães.

O cão jovem tem sido considerado como o modelo experimental adequado para o estudo da doença de Chagas na fase aguda por reproduzir com fidelidade vários aspectos da infecção humana 211 . Além disso, o estudo da fase aguda da infecção induzida pelo Trypanosoma cruzi pode ser de grande importância considerando que diferentes autores têm sugerido que muitas das lesões tardias são influenciadas pelo curso da doença nesse estágio da doença ${ }^{3} 15$. Por outro lado, o estudo do comportamento de várias cepas do $T$. cruzi em diferentes hospedeiros experimentais parece indicar que o parasita influencia nas caracteristicas da infecção aguda. Entre as diferentes populações do T. cruzi as cepas Y e CL mostraram no camundongo aspectos praticamente polares em relação à morfologia das formas sangüineas, curvas de parasitemia, mortalidade, susceptibilidade à quimioterápicos e distribuição de parasitas nos diferentes tecidos e células do hospedeiro ${ }^{7}$. Nos estudos realizados mais recentemente em coelhos foram também observadas diferenças significativas nas curvas de parasitemia e outras características da infecção aguda nos animais inoculados com as cepas $\mathrm{Y}$ e $\mathrm{CL}$, seja como formas sangüineas ou com tripomastigotas metacíclicos obtidos do vetor ${ }^{13} 14$.

\footnotetext{
* Centro de Pesquisas René Rachou, FIOCRUZ, Av. Augusto de Lima, 1715 - C.P. 1743 - 30.000 - Belo Horizonte - MG - Brasil.

Trabalho realizado com auxilio do Conselho Nacional de Pesquisas, Brasil.
}

Recebido para publicação em 15/4/85
Tendo em vista a possível importância desses achados e, sobretudo, a ausência na literatura de dados mais detalhados sobre o curso da infecção, do ponto de vista parasitológico, em cães inoculados com diferentes populações do $T$. cruzi, estudamos, através de métodos parasitológicos e anatomopatológicos, o comportamento de cães jovens inoculados com as cepas Y e CL desse parasita.

\section{MATERIAL E MÉTODOS}

Cepa do T. cruzi Y, isolada de um caso humano por Silva e Nussenzweig 17 ; CL, isolada de Triatoma infestans naturalmente infectado, coletado em domicilio, no Estado do Rio Grande do Sul, Brasil $^{8}$.

Infecção dos cães. Foram utilizados 30 cães mestiços, com três meses de idade, de ambos os sexos, provenientes de várias ninhadas, pesando 3 a $4,5 \mathrm{~kg}$. Após o desmame, os animais foram submetidos à dieta padrão comercial ad libitum, tratamento antihelmintico (Combantrim - Pfizer); vacinas contra leptospirose, cinomose e hepatite (Smith Kline USA). dos:

Os seguintes grupos de animais foram estuda-

a) Dois grupos de 9 animais, inoculados com $10^{7}$ tripomastigotas sanguíneos das cepas Y e CL, respectivamente, por via intraperitoneal. Os tripomastigotas sangüineos foram obtidos a partir de sangue de camundongos experimentalmente infectados com as cepas Y e CL, coletado no 7. e 14. dia da 
Castro MAP, Brener Z. Estudo parasitológico e anátomo-patológico da fase aguda da doenca de Chagas em cães inoculados com duas diferentes cepas do Trypanosoma cruzi. Revista da Sociedade Brasileira de Medicina Tropical 18: 223-229, Out-Dez, 1985

infecção, respectivamente. A contagem dos tripomastigotas foi realizada segundo a técnica de Brener ${ }^{5}$.

b) Dois grupos de 3 animais foram infectados por via conjuntival com $2 \times 10^{3}$ tripomastigotas metacíclicos das cepas $\mathrm{Y}$ e $\mathrm{CL}$ provenientes de triatomineos (Dipetalogaster maximus) experimentalmente infectados. Os parasitas foram obtidos ou a partir da maceração do intestino ou, então, de fezes eliminadas espontaneamente e colhidas em solução salina. A contagem dos parasitas foi realizada em câmara de Neubauer. A inoculação dos cães foi realizada através do auxilio de pipeta automática que permitia colocar na mucosa conjuntival, gotas previamente calculadas do material infectante. controle.

c) Um grupo de 6 cães normais foi usado como

Estudo parasitológico. A parasitemia foi observada diariamente, a partir do 4 ? dia da infecção, segundo a técnica de Brener ${ }^{5}$. O xenodiagnóstico foi realizado somente nos casos em que o parasita não era detectado no sangue periférico, sendo o exame feito utilizando-se 40 ninfas de terceiro estágio de $T$. infestans.

Estudo anatomopatológico. Os animais mortos espontaneamente ou sacrificados com Nembutal sódico foram submetidos à necropsia completa. Os cães foram estudados aos pares (um inoculado com a cepa Y e outro com a cepa CL) $8,11,15,17,19,20$, 22,25 e 28 dias após a infecção por via intraperitoneal e 30, 35 e 40 dias após a infecção por via conjuntival.

Fragmentos das câmaras atriais e ventriculares, septo e ponta do coração foram retirados, fixados em formol salina a $10 \%$, incluídos em parafina para estudo microscópico em secções corados pela hematoxilina-eosina com $5 \mu \mathrm{m}$ de espessura. Foram igualmente colhidos fragmentos de músculo esquelético, órgãos do sistema digestivo, fígado, baço, pâncreas. pulmão e sistema nervoso central.

O grau de parasitismo do coração foi estimado a partir da determinação do número de pseudocistos observados em 50 campos microscópicos x (400), em microscópio Zeiss, em cada um dos três cortes examinados. Consideraram-se como $(++++)$ as preparações nas quais em praticamente todos os campos microscópicos foram encontrados pseudocistos; $(++)$, quando eram encontrados 5 ou menos pseudocistos nos 50 campos microscópicos examinados; $(+++)$, graus intermediários de parasitismo; $(+)$, quando os parasitas eram extremamente raros, só sendo encontrados após exame de mais de 50 campos; (-), quando parasitas não eram observados mesmo após exame exaustivo do corte histológico.

A intensidade da reação inflamatória foi estimada segundo o seguinte critério: $(-)$, Ausente; $(+)$, infiltrado inflamatório discreto, sem formar focos; $(++)$, infiltrado inflamatório discreto, formando pequenos focos; $(+++)$, focos inflamatórios extensos e confluentes em algumas áreas e esparsos em outras; $(++++)$, infiltrado inflamatório difuso e acentuado.

\section{RESULTADOS}

As cepas $\mathrm{Y}$ e CL induziram diferentes cursos de parasitemia no cão, independentemente do inóculo e via de inoculação utilizados. Com a cepa $\mathrm{CL}$ a parasitemia tornou-se patente em todos os animais inoculados com formas sanguineas por via intraperitoneal, entre o 7. e 9 ${ }^{\circ}$ dia da infecção. Os niveis parasitêmicos foram sempre elevados e caracterizaram-se por uma ascensão gradual durante o curso da infecção, que se estendeu do 7० ao 27\% dia (Figura 1). Com a cepa $\mathrm{Y}$, o número de parasitas circulantes foi significativamente menor, parasitemia foi detectada em 7 dos 9 animais inoculados intraperitonealmente, entre $07 \circ^{\circ}$ e 13\% dia da infecção, declinando rapidamente; a configuração das curvas de parasitemia foi caracterizada por pequena elevação inicial, seguida de picos parasitemicos irregulares de baixa parasitemia e de um periodo patente bastante curto, nunca superior a 13 dias (Fig. 1). Nos dois animais nos quais a parasitemia foi subpatente parasitas só foram detectados por xenodiagnóstico.

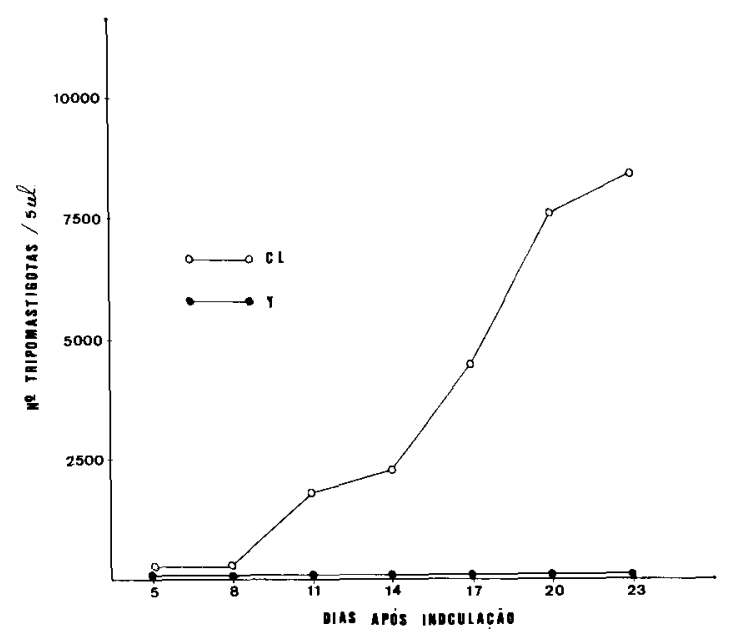

Figura 1-Curvas de parasitemia em cães inoculados por via intraperitonial com $10^{7}$ formas sangüineas das cepas $Y$ e $C L$ de T. cruzi No animal inoculado com a cepa $Y$ a parasitemia foi subpatente e somente detectada por xenodiagnóstico.

Diferenças semelhantes na parasitemia foram também observadas nos grupos de animais infectados com tripomastigotas obtidos do vetor (Fig. 2). Os cães inoculados com a cepa CL comportaram-se de maneira semelhante aos cães inoculados intraperitonealmente com formas sanguíneas, com exceção apenas do inicio do período patente que ocorreu a partir do 17\% dia. Com a cepa Y, em dois animais a parasitemia foi patente, apresentando picos irregulares (Fig. 2) enquanto que nos outros dois cáes a 
Castro MAP, Brener Z. Estudo parasitológico e anátomo-patológico da fase aguda da doença de Chagas em cães inoculados com duas diferentes cepas do Trypanosoma cruzi. Revista da Sociedade Brasileira de Medicina Tropical 18: 223-229, Out-Dez, 1985

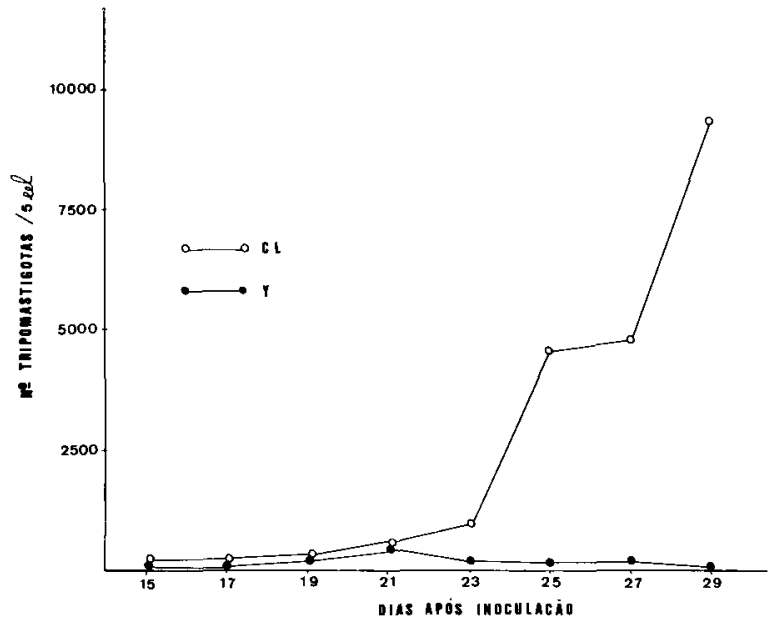

Figura 2 - Curvas de parasitemia em cães inoculados por via conjuntival com $2 \times 10^{3}$ tripomastigotas metaciclicos obtidos de triatomíneos (Dipetalogaster maximus) experimentalmente infectados com as cepas $Y$ e $C L$.

parasitemia foi subpatente e somente detectada por xenodiagnóstico.

O maior indice de mortalidade foi verificada nos animais infectados com a cepa $Y$. De 4 animais que faleceram durante o curso de infecção, 3 haviam sido infectados com a cepa Y. Entretanto, não foi observada correlação entre parasitemia e mortalidade, em vista desses animais terem apresentado baixos niveis parasitêmicos e o óbito ter ocorrido após o desaparecimento de parasitas do sangue periférico.

Ao exame microscópico foi observado que os animais inoculados com as cepas $\mathrm{Y}$ e CL comportaram-se de maneira semelhante em relação à distribuição tissular de parasitas, porém mostrando diferenças no que se refere aos aspectos anatomopatológicos das lesões. Com ambas as cepas o parasitismo e as lesões predominaram no miocárdio e foram de intensidade variável nos músculos estriados esqueléticos e lisos. Nos demais órgãos ocorreram lesōes aparentemente independentes da presença do parasita. Em nenhum dos animais inoculados com as cepas $\mathrm{Y}$ e $\mathrm{CL}$, mesmo nas fases mais precoces da infecção, foram detectados parasitas em células macrofágicas do baço e fígado.

No coração, o parasitismo e as lesões tissulares caracterizadas por uma inflamação com exsudato predominantemente mononuclear foram, desde as fases iniciais, nitidamente mais acentuadas nos atrios, quando comparadas com o pequeno ou raro envolvimento dos ventrículos (paredes, septo intraventricular e ponta) (Tabelas 1, 2 e 3). Entretanto, as lesões cardiacas, induzidas por ambas as populações do parasita, mostraram diferenças. Com a cepa $Y$, a miocardite foi intensa desde as fases mais precoces da infeç̧ão, enquanto com a cepa $\mathrm{CL}$ o processo inflamatório tornou-se acentuado somente a partir do 17. dia após a inoculação (Prancha 1). Nos animais inoculados com a cepa $Y$, o parasitismo nos átrios foi bastante acentuado até o 15 . dia da infecção e podia ser correlacionado com a intensa miocardite enquanto que nos ventrículos o parasitismo foi relativamente escasso ao longo da infecção. Havia igualmente discreto grau de parasitismo e das lesōes nos animais inoculados com a cepa CL e examinados neste periodo. Entretanto, a partir do 17 . dia da $^{\circ}$ infecção foi observado que a miocardite tornava-se cada vez mais intensa, enquanto que o parasitismo das fibras cardíacas era bastante discreto ou até mesmo ausente, independente da cepa, inóculo e vias de inoculação (Tabelas 1, 2 e 3). Essa falta de relação entre a intensidade da reação inflamatória e o parasitismo observada inicialmente no coração foi também demonstrada nos músculos esqueléticos e lisos.

Tabela 1 - Intensidade do parasitismo tissular e reação inflamatória no coração de cães inoculados por via conjuntival com $10^{3}$ tripomastigotas metaciclicos obtidos de triatomíneos (D. maximus) experimentalmente infectadas com as cepas $\mathrm{Y}$ e $\mathrm{CL}$.

\begin{tabular}{|c|c|c|c|c|c|c|c|c|}
\hline \multirow{2}{*}{$\begin{array}{c}N .{ }^{\circ} \\
\text { animal }\end{array}$} & \multirow[b]{2}{*}{ Cepa } & \multirow{2}{*}{$\begin{array}{c}\text { Dias } \\
\text { de } \\
\text { Infecção }\end{array}$} & \multicolumn{6}{|c|}{ Ventrículo } \\
\hline & & & $P$ & $R I$ & $\begin{array}{c}\text { Parede } \\
P\end{array}$ & $\begin{array}{c}\text { Septo } \\
R I\end{array}$ & $P$ & $R I$ \\
\hline 27 & $\mathrm{Y}$ & 30 & - & ++++ & - & +++ & + & +++ \\
\hline 39 & $\mathbf{Y}$ & 35 & - & +++ & - & +++ & + & + \\
\hline 40 & Y & 40 & + & $+++t$ & + & $++t$ & - & + \\
\hline 24 & CL & 30 & + & ++++ & - & +++ & + & + \\
\hline 23 & CL & 35 & - & ++++ & + & ++ & - & ++ \\
\hline 21 & CL & 40 & - & +++ & - & + & - & + \\
\hline
\end{tabular}

P - Parasitismo tissular; RI - Reação inflamatória 
Castro MAP, Brener Z. Estudo parasitológico e anátomo-paiológico da fase aguda da doenca de Chagas em cäes inoculados com duas diferentes cepas do Trypanosoma cruzi. Revista da Sociedade Brasileira de Medicina Tropical 18: 223-229, Out-Dez, 1985

Tabela 2 - Intensidade do parasitismo tissular e reação inflamatória no coração de cães inoculados por via intraperitoneal com $10^{6}$ formas sangüineas da Cepa $C L$ do T. cruzi.

\begin{tabular}{cccccccc}
\hline No & $\begin{array}{c}\text { Dias } \\
\text { de }\end{array}$ & & \multicolumn{1}{c}{ Atrio } & \multicolumn{2}{c}{ Ventriculo } \\
animal & infecçáo & $P$ & & $R I$ & $P$ & Papto & \multicolumn{2}{c}{ Apice } \\
\hline 28 & 8 & - & - & - & - & - & - \\
41 & 11 & + & + & + & - & - & - \\
29 & 15 & - & ++ & + & + & + & + \\
8 & 17 & +++ & +++ & - & +++ & - & + \\
1 & 19 & + & +++ & + & + & + & + \\
10 & 20 & - & +++ & - & + & + & - \\
2 & 22 & ++ & ++++ & - & ++ & - & + \\
43 & 25 & - & ++++ & - & + & - & ++ \\
42 & 28 & + & ++++ & + & ++ & - & + \\
\hline
\end{tabular}

P - Parasitismo tissular; RI - Reação inflamatória

Tabela 3 - Intensidade do parasitismo tissulare reaçào inflamatória no coraçào de cáes inoculados por via intraperitoneal com $10^{6}$ formas sangüineas da Cepa $Y$ de $\mathrm{T}$. cruzi.

\begin{tabular}{|c|c|c|c|c|c|c|c|}
\hline \multirow{3}{*}{$\begin{array}{c}\text { No } \\
\text { animal }\end{array}$} & \multirow{3}{*}{$\begin{array}{c}\text { Dias } \\
\text { de } \\
\text { infeç̧âo }\end{array}$} & \multicolumn{6}{|c|}{ Ventriculo } \\
\hline & & \multicolumn{2}{|c|}{ Átrio } & \multirow{2}{*}{$\begin{array}{c}\text { Parede } \\
P\end{array}$} & \multirow{2}{*}{$\begin{array}{c}\text { Septo } \\
R I\end{array}$} & \multicolumn{2}{|c|}{ Ápice } \\
\hline & & $P$ & $R I$ & & & $P$ & $R I$ \\
\hline 26 & 8 & + & $++t$ & + & ++ & + & + \\
\hline 45 & 11 & ++ & ++++ & - & +++ & - & ++ \\
\hline 6 & 15 & +++ & ++++ & ++ & +++ & + & + \\
\hline 44 & 17 & + & ++++ & - & +++ & + & + \\
\hline 3 & 19 & - & ++++ & + & ++ & - & + \\
\hline 46 & 20 & + & ++++ & - & ++ & - & - \\
\hline 9 & 22 & -. & ++++ & _- & +++ & + & ++ \\
\hline 7 & 25 & ++ & +++ & _- & +++ & + & ++ \\
\hline 4 & 28 & - & ++++ & _- & ++ & - & + \\
\hline
\end{tabular}

P - Parasitismo tissular; RI - Reação inflamatória

As lesōes do músculo esquelético foram sempre mais intensas e freqüentes nos animais inoculados com a cepa $\mathrm{CL}$, do que com a $\mathrm{Y}$, desde o inicio da infecção. As lesões regressivas das células musculares, de um modo geral, foram freqüentes e graves como perda de estriação, hialinização e fragmentação das fibras. Todavia, tais fenômenos nem sempre foram diretamente relacionados ao parasitismo local e/ou a reação inflamatória.

A reação inflamatória nos plexos do Sistema Nervoso Autônomo do coração e tubo digestivo esteve presente em todos os grupos estudados, sendo mais freqüente no coraçao dos animais inoculados com a cepa $\mathrm{Y}$ e no tubo digestivo de animais inoculados com a cepa CL. Em nenhum dos cães foi observado parasitismo das células nervosas ganglionares.

Não foram observadas alterações histológicas significativas nos 6 animais controles não infectados.

\section{DISCUSSÃO}

O diferente comportamento da parasitemia induzida pelas cepas $\mathrm{Y}$ e CL nos cães usados em nossas experiências foi nitidamente observado quer quando o inoculo foi constituido por formas sangüineas quer por tripomastigotas metacíclicos obtidos de triatomineos infectados. Essas observacoões coincidem com as descrições de Ramirez e Brener ${ }^{14}$ e Ramirez ${ }^{13}$ sobre a parasitemia de coelhos infectados com ambas as cepas, confirmando o aspecto "polar" do comportamento dessas duas populaçōes do $T$. cruzi em camundongos ${ }^{7}$. Esse comportamento homogêneo das duas cepas nos diferentes hospedeiros sugere fortemente que certos aspectos parasitológicos observados no nosso material são determinados por fatores relacionados ao parasita e à modulação imunológica do hospedeiro, já descritos em trabalhos anteriores. Assim, as formas sangüineas largas que predominam 
Castro MAP, Brener Z. Estudo parasitológico e anátomo-patológico da fase aguda da doença de Chagas em cāes inoculados com duas diferentes cepas do Trypanosoma cruzi. Revista da Sociedade Brasileira de Medicina Tropical 18: 223-229, Out-Dez, 1985

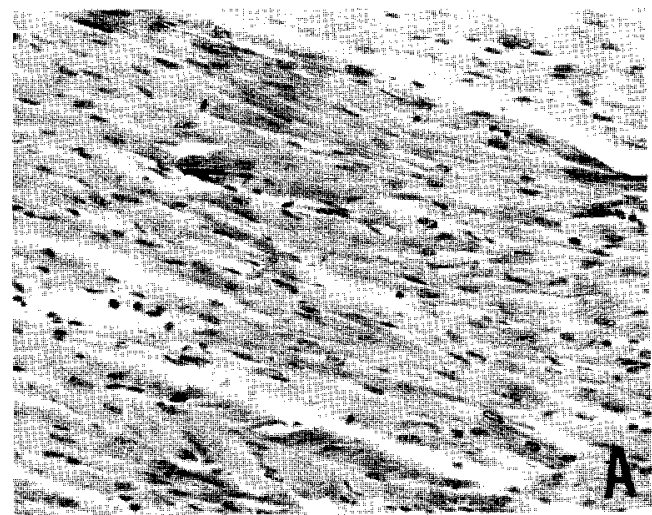

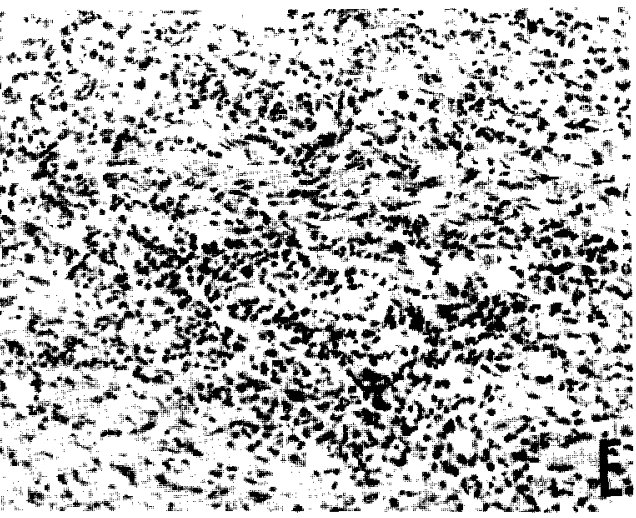

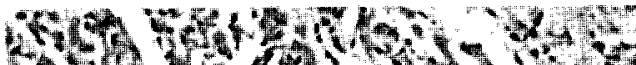

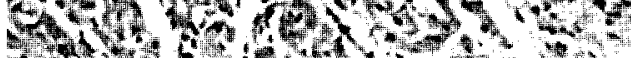

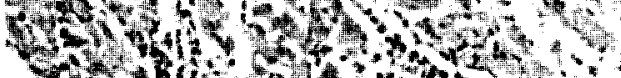

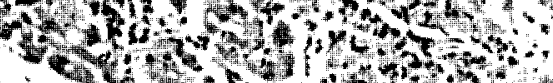

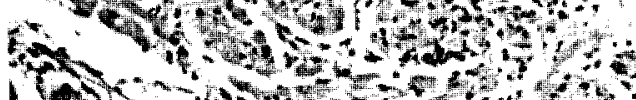

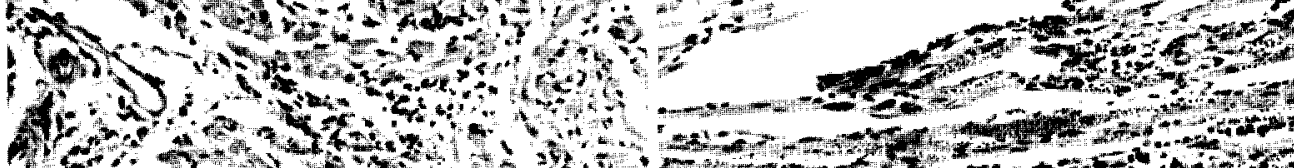

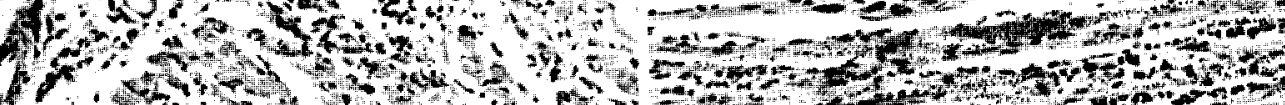

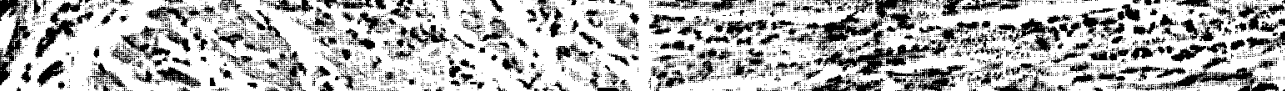

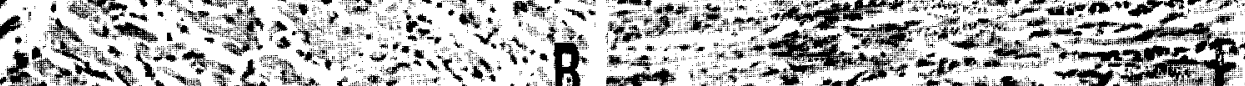

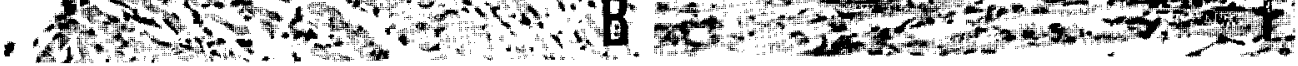

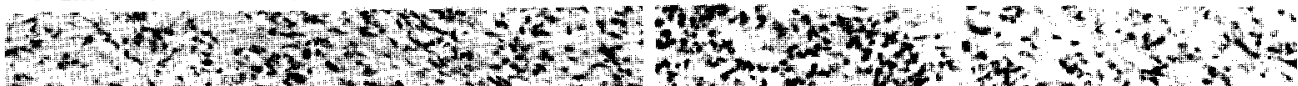

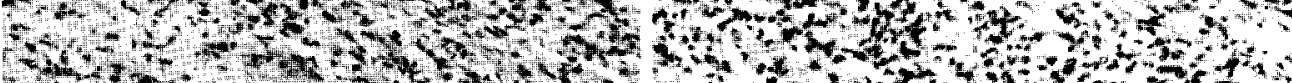

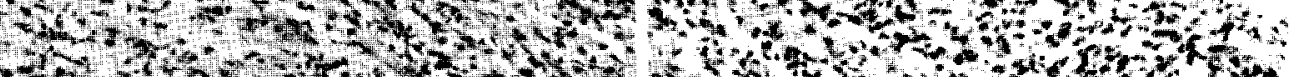

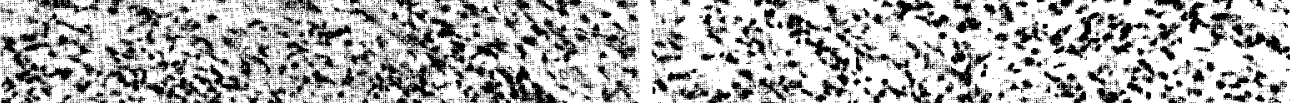

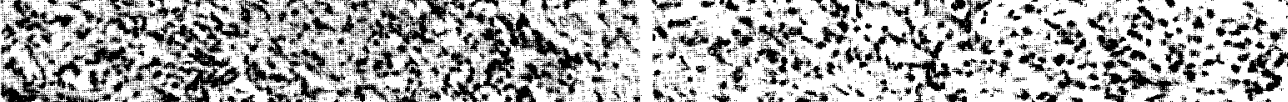

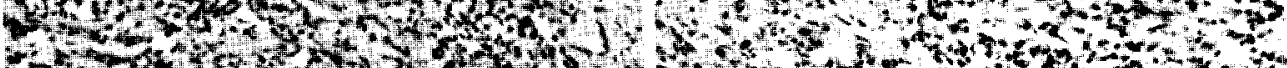

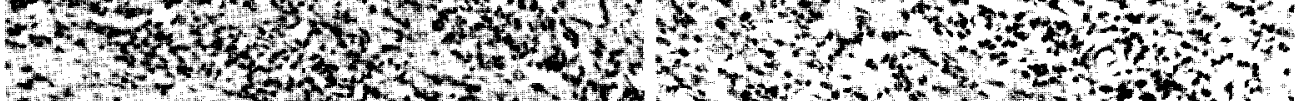

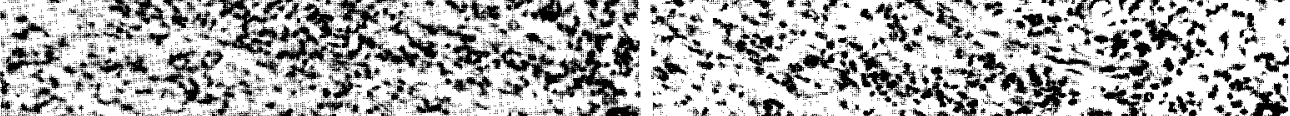

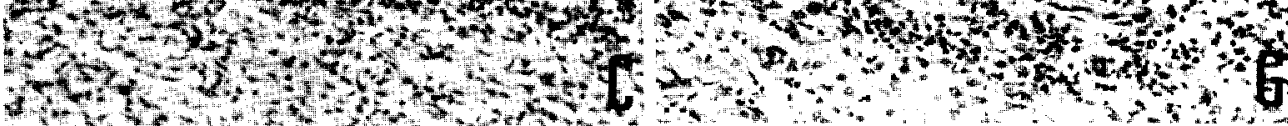

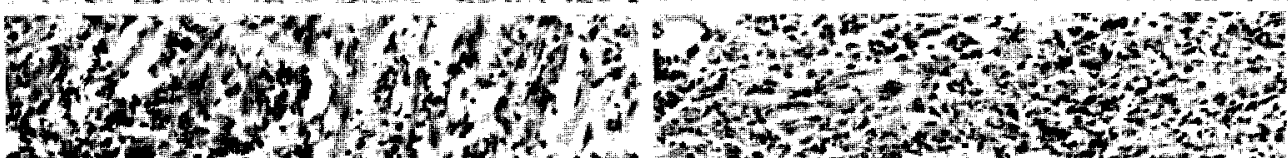

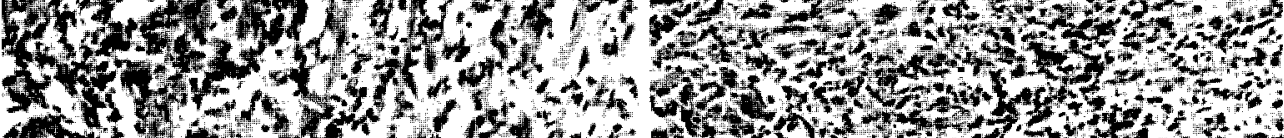

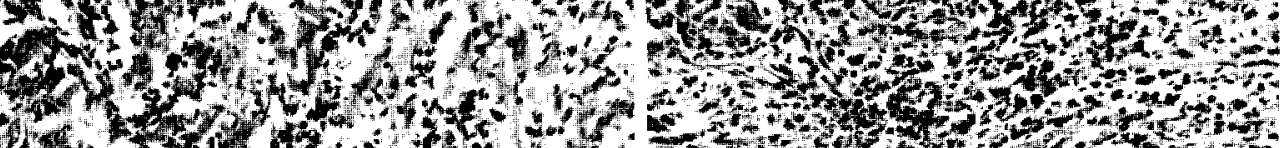

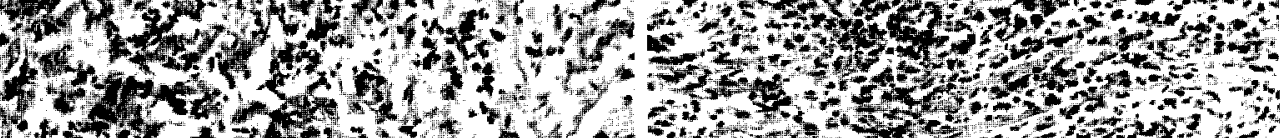

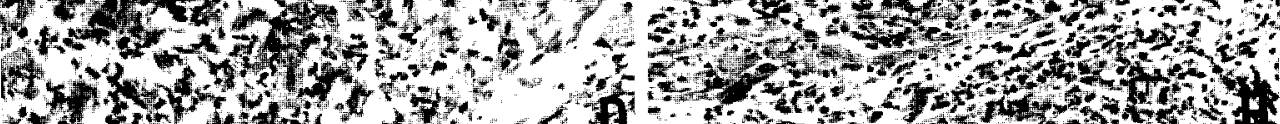

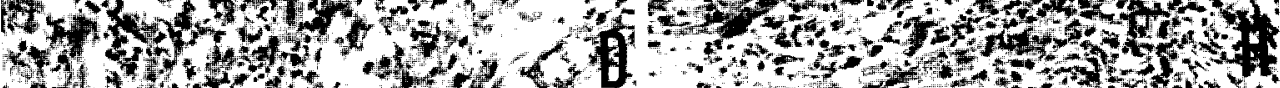

Figura 3-Miocardite atrial em cães inoculados com T. cruzi Figs. A, B, C, D: animais inoculados com $10^{7}$ formas sangüineas da cepa $C L$, sacrificados no 8., 15., $20^{\circ}$ e $25^{\circ}$ dias de infeção, respectivamente. Figs. $E, F, G, H$ : animais inoculados com $10^{7}$ formas sangüineas da cepa $Y$, sacrificados nos mesmos dias que o grupoanterior. Notar que a intensidade da miocardite nas fases iniciais da infeccáa é significativamente maior com a cepa $Y$. 
Castro MAP, Brener Z. Estudo parasitológico e anátomo-patológico da fase aguda da doença de Chagas em cães inoculados com duas diferentes cepas do Trypanosoma cruzi. Revista da Sociedade Brasileira de Medicina Tropical 18: 223-229, Out-Dez, 1985

na cepa CL (e também MR) apresentam uma capacidade de interiorização nos tecidos significativamente menor que as formas delgadas predominante na cepa $\mathrm{Y}^{469}$. Há evidências de que essas propriedades biológicas estejam relacionadas ao polimorfismo do $T$. cruzi. Assim, Schmatz e cols 16 separaram, através de um gradiente continuo de "hypaque", as formas largas e delgadas de mioblastos infectados com a cepa $\mathrm{Y}$ e demonstraram que as formas delgadas são muito mais infectantes para essas células que as largas. De outro lado, as formas largas sangüíneas que predominam na cepa $\mathrm{CL}$ apresentam maior resistência à resposta imune humoral do hospedeiro que as formas sangüineas delgadas da cepa $Y^{10}$. De um modo geral, o comportamento dessas duas populações parasitárias poderia explicar algumas das diferenças encontradas nos cães, a saber: o longo período patente e a alta parasitemia induzida pela cepa CL que contrastam com o curto periodo patente e a baixa irregular parasitemia observada $\operatorname{com} \mathrm{Y}$; o fato de que, independentemente do inóculo e via de inoculação, parasitas foram detectados em todos os animais inoculados com a cepa CL enquanto que com a cepa $Y$ em $25 \%$ dos animais a parasitemia foi subpatente e somente detectada por xenodiagnóstico; finalmente, $o$ parasitismo tissular cardiaco mais intenso e mais precoce encontrado nos animais inoculados com a cepa $\mathrm{Y}$, sugerindo rápida interiorização das formas sangüineas.

Essas observações parasitológicas confirmam mais uma vez que em populaçōes de $T$. cruzi amplificadas por passagens sucessivas em animais expressa-se uma dualidade de comportamento das formas sangüineas que persiste mesmo após passagem dos parasitas pelo vetor e uso dos tripomastigotas metacíclicos como estágios infectantes. As implicaçōes desses achados no ciclo evolutivo e na morbidade das infecções na natureza permanecem obscuras.

No coração o parasitismo e as lesões tissulares caracterizadas por inflamação com exsudato predominantemente mononuclear foram, desde as fases iniciais da infecção, nitidamente mais acentuadas nos átrios quando comparados com o pequeno ou raro envolvimento dos ventrículos (paredes, septo intraventricular e ponta). Esses achados estão de acordo com a descrição de Andrade e Andradel que observaram o inicio da miocardite na aurícula direita com conseqüente propagação para a parte direita do septo $\mathrm{e}$ a parede livre do ventrículo direito. No entanto, as lesões cardíacas induzidas por ambas as populações parasitárias mostraram diferenças quanto à sua evolução. Com a cepa Y a miocardite foi intensa desde as fases mais precoces da infecção enquanto que com a cepa CL o processo inflamatório tornou-se acentuado somente a partir do 17! dia de infecção refletindo, provavelmente, as peculiaridades do parasitismo. Um aspecto importante foi, sobretudo nas fases mais tardias da infecção aguda, a falta de relação entre o parasitismo tissular e a intensidade da reação inflamatória no coração e também na musculatura esquelética e lisa. Por outro lado, a intensidade da miocardite observada em alguns animais, sobretudo os inoculados com a cepa $Y$, não correspondia à parasitemia. Em pelo menos dois cães inoculados com essa cepa e nos quais a infecção só foi diagnosticada pelo xenodiagnóstico, a miocardite foi intensa e comparável àquela observada nos animais com parasitemia patente. Esses achados sugerem fortemente a existência de mecanismos imunológicos na gênese das lesões cardíacas descritas no nosso material. A determinação da natureza das células que compõem o processo inflamatório da miocardite aguda no cão, através de métodos histoquímicos, mostra que o quadro morfológico poderia ser interpretado como uma expressão de resposta imune celular ${ }^{12}$.

\section{SUMMARY}

Young dogs were inoculated with T. cruzi $Y$ and $C L$ strains either by intraperitoneal route with $10^{7}$ blood forms or by ocular route with $2 \times 10^{3}$ vector-derived trypomastigotes. With both inocula the patterns of parasitemia were significantly different, confirming data previously obtained in experimentally infected mice and rabbits. CL strain induced a gradual ascencional parasitemia whereas with $Y$ the parasitemia was either subpatent or the number of parasites was very low, rapidly declining. Although myocarditis was present in most animals regardless of the strain used, the inflammatory process was established earlier with the Y strain. The severity of the myocarditis was not related to parasitemia and in some animals in which parasites could only be detected by xenodiagnosis the lesions were comparable to those detected in animals with high number of blood forms. In a similar way, no correlation was established between tissue parasitism and myocardium inflammatory lesions. Thus, the heart tissue damage in the acute phase was not apparently influenced by the differences in the course of infection, suggesting $a$ participation of immunological mechanisms even at this early stage of infection.

Key words: Trypanosoma cruzi $Y$ and $C L$ strains. Dog's experimental myocarditis.

\section{REFERÊNCIAS BIBLIOGRÁFICAS}

1. Andrade ZA, Andrade SG. A patologia da doença de Chagas experimental no cão. Memórias do Instituto Oswaldo Cruz 75: 77-96, 1980.

2. Andrade ZA, Andrade SG, Sadigursky M, Lima JAC. Doença de Chagas experimental no cão. Relação morfológica e eletrocardiográfica na fase aguda da infecção. Arquivos Brasileiros de Cardiologia 35:485-500, 1980.

3. Andrade ZA, Andrade SG, Sadigursky M, Manguire JM. Experimental Chagas' disease in dogs. A pathological and ECG study of the chronic indeterminate phase of the infection. Archives of Pathology and Laboratory Medicine 105: 460-464, 1981.

4. Bertelli MSM, Brener Z. Infection of tissue culture cells with bloodstream trypomastigotes of Trypanosoma cruzi. Journal of Parasitology 66:992-997, 1981. 
Castro MAP, Brener Z. Estudo parasitológico e anátomo-patológico da fase aguda da doença de Chagas em cães inoculados com duas diferentes cepas do Trypanosoma cruzi. Revista da Sociedade Brasileira de Medicina Tropical 18: 223-229, Out-Dez, 1985

5. Brener $Z$. Therapeutic activity and criterion of cure on mice experimentally infected with Trypanosoma cruzi. Revista do Instituto de Medicina Tropical de São Paulo 4: 389-396, 1962.

6. Brener $Z$. The behaviour of slender and stout forms of Trypanosoma cruz $i$ in the bloodstream of normal and immune mice. Annals of Tropical Medicine and $\mathrm{Pa}-$ rasitology 63: 215-220, 1969.

7. Brener Z. Intraspecific variation in Trypanosoma cruzi: two types of parasite populations presenting distinct features. In: Chagas' Disease, Pan American Health Organization, Scientific Publication n. 347: 11-21, 1977.

8. Brener Z, Chiari E. Variações morfológicas observadas em diferentes amostras de Trypanosoma cruzi. Revista do Instituto de Medicina Tropical de São Paulo 5:220$227,1963$.

9. Howells RE, Chiari CA. Observations on two strains of Trypanosoma cruzi in laboratory mice. Annals of Tropical Medicine and Parasitology 69: 435-448, 1975.

10. Krettli AU, Brener $Z$. Protective effects of specific antibodies on Trypanosoma cruzi infection. Journal of Immunology 116: 755-760, 1976.

11. Laranja FS. Aspectos clínicos da moléstia de Chagas. Revista Brasileira de Medicina 10: 482-491, 1953.
12. Pedreira de Castro MA, Brener Z. Characterization of inflammatory cells in acute myocardites of dogs infected with Trypanosoma cruzi. In: Resumos da VIII Reuniào Anual sobre Pesquisa Básica em Doença de Chagas, Caxambu, p. 35, 1981.

13. Ramirez LE. O coelho como modelo experimental no estudo da doença de Chagas crónica. Tese de Doutorado, Departamento de Parasitologia, Instituto de Ciências Biológicas da Universidade Federal de Minas Gerais, 1984.

14. Ramirez LE, Brener Z. Acute phase of experimental Chagas' disease in rabbits: I. Parasitological aspects. In: Resumos da VIII Reunião Anual sobre Pesquisa Básica em Doença de Chagas, Caxambu, p. 29, 1981.

15. Ribeiro dos Santos R, Hudson L. Denervation and immune response in mice infected with Trypanosoma cruzi. Clinical and Experimental Immunology 44: 349-354, 1981.

16. Schmatz DM, Boltz RC, Murray PK. Trypanosoma cruzi: separation of broad and slender trypomastigotes using a continuous hypaque gradient. Parasitology 87: 219-227, 1983.

17. Silva LHP, Nussenzweig V. Sobre uma cepa de Trypanosoma cruzi altamente virulenta para o camundongo branco. Folia Clinica et Biologica 20: 191-208, 1953. 